\title{
Differences between psychopathy and other personality disorders: evidence from neuroimaging
}

\author{
Sagari Sarkar, Ben S. Clark \& Quinton Deeley
}

\begin{abstract}
SUMMARY
ICD-10 and DSM-IV-TR diagnostic guidelines do not list psychopathy as a distinct psychiatric entity. However, there are significant overlaps between psychopathy and DSM-IV-TR Cluster B personality disorders. Neuroimaging studies implicate deficits in structure and function of frontal and limbic regions in this group of personality disorders, while highlighting both distinctions and overlaps between syndromes. Here, these data are reviewed and implications for diagnosis and clinical practice are discussed.
\end{abstract}

\section{DECLARATION OF INTEREST}

None.

In his influential book The Mask of Sanity, Hervey Cleckley presented a series of vignettes which distilled typical features of large numbers of individuals with psychopathy whom he had interviewed (Cleckley 1941). He described them as charming, callous and superficial, commenting that their lack of conscience or genuine emotion was camouflaged by the 'mask' of a healthy, functional individual. People with psychopathy commit a large amount and wide variety of violent and non-violent crimes, and are resistant to attempts at rehabilitation (Reid 2000). The definition of psychopathy has changed little since Cleckley's time, and the aetiology of the condition remains unknown.

Psychopathy shares general features with personality disorders listed in DSM-IV-TR (American Psychiatric Association 2000), even though it is not included among them. Personality disorders comprise a group of disorders that usually result in impaired interpersonal functioning. Individuals exhibit enduring patterns of cognition, emotion and behaviour that deviate markedly from cultural expectations. The three clusters of personality disorders listed by the DSM-IV-TR (American Psychiatric Association 2000) fall under the headings 'odd-eccentric' (Cluster A), 'emotionaldramatic' (Cluster B) and 'anxious-fearful' (Cluster C), and each contains further subtypes.

\section{Reclassification of psychopathy}

Since the publication of DSM-III (American Psychiatric Association 1980), psychopathy is no longer listed as a distinct psychiatric condition. In current diagnostic classifications psychopathy is regarded as being synonymous with antisocial personality disorder in DSM-IV-TR (American Psychiatric Association 2000) and dissocial personality disorder in ICD-10 (World Health Organization 2004). However, although both antisocial and dissocial personality disorders include several traits reflecting psychopathic personality (e.g. lack of guilt/remorse, impulsivity), it is possible to meet the diagnostic criteria for these disorders based on just the behavioural manifestations of antisocial behaviour (e.g. violation of social norms, irresponsibility, criminality). Hence, the emotional dysfunction at the core of Cleckley's notion of 'the psychopath' is not essential for antisocial or dissocial personality disorder, even if it is present in some cases. The Psychopathy Checklist (PCL; Hare 1980) and the later Psychopathy Checklist Revised (PCL-R; Hare 1991, 2003) were therefore designed to operationalise Cleckley's psychopathy construct to provide a formal diagnostic instrument for the disorder. The PCL-R is considered by many to be the gold standard instrument for this disorder (Morana 2005).

\section{Assessment of psychopathy and personality disorder}

The PCL-R consists of 20 items falling broadly into two dimensions: Factor 1 items are predominantly emotional or interpersonal traits such as deception, remorselessness, shallow affect and callousness, whereas Factor 2 items assess behavioural manifestations of the disorder such as criminality, violence and dysfunctional lifestyle (Box 1). Characteristics from both these factors are needed for a diagnosis of psychopathy to be made. Although many consider the first dimension to differentiate psychopathy from other personality disorders (Kiehl 2006), there is considerable overlap between a number of these traits, not only
Sagari Sarkar is a doctoral student at the Institute of Psychiatry, King's College London. Her research examines the neurobiological antecedents and correlates of childhood antisocial behaviour and other developmental psychopathologies. Ben S. Clark is a psychiatrist in the Springs Unit, Cygnet Hospital Harrow, London. His research interests include liaison psychiatry in palliative care, with a particular interest in the needs of individuals with personality disorders or other mental illness and life-limiting physical illness. Quinton Deeley is a senior lecturer in social behaviour and neurodevelopment at the Institute of Psychiatry, King's College London. He undertakes research into disorders of social cognition such as autism-spectrum disorders and personality disorders, dissociative processes and cultural neuroscience. His clinical work is based at the MIETS Unit, Bethlem Royal Hospital, Kent, the Behavioural Genetics Clinic at the Maudsley Hospital, London, and at the Springs Unit, Cygnet Hospital Harrow.

Correspondence Quinton Deeley, Department of Psychological Medicine, Institute of Psychiatry, De Crespigny Park, London SE5 8A5, UK. Email: peter.q.deeley@kcl.ac.uk 


\section{BOX 1 The 20 items of the Psychopathy Checklist - Revised (PCL-R)}

\begin{tabular}{ll}
\hline Factor 1 & - Lack of realistic, long-term goals \\
Interpersonal & - Impulsivity \\
- Glibness - superficial charm & - Irresponsibility \\
- Grandiose sense of self-worth & Antisocial \\
- Pathological lying & - Poor behavioural control \\
- Conning - manipulative & - Early behavioural problems \\
Affective & - Juvenile delinquency \\
- Lack of remorse or guilt & - Revocation of conditional release \\
- Shallow affect & - Criminal versatility \\
- Callous - lack of empathy & Additional items 'Promiscuous sexual \\
- Failure to accept responsibility & behaviour' and 'Many short-term marital \\
Factor 2 & relationships' do not load onto these two \\
Lifestyle & factors but contribute to an individual's \\
- Need for stimulation & score on this instrument. \\
- Parasitic lifestyle &
\end{tabular}

between psychopathy and antisocial/dissocial personality disorder, but also between psychopathy and other DSM-IV Cluster B disorders (Table 1), including borderline, histrionic and narcissistic personality disorders. This supports the view that psychopathy comprises a 'higher order' collection of disordered personality traits from many categories (Blackburn 2005).

Following a brief overview of psychopathy and the Cluster B disorders, this article reviews neurobiological correlates of psychopathy, antisocial and borderline personality disorders, focusing on findings from neuroimaging research.

\section{Psychopathy}

Recent epidemiological studies of psychopathy report that it occurs in about $0.6 \%$ of the general population (Coid 2009a) and $7.7 \%$ of male

TABLE 1 Common traits between Cluster B personality disorders (DSM-IV-TR) and psychopathy (PCL-R)

\begin{tabular}{|lll|}
\hline Subtype & DSM-IV-TR trait & PCL-R trait \\
\hline $\begin{array}{l}\text { Antisocial } \\
\text { personality disorder }\end{array}$ & $\begin{array}{l}\text { Engagement in illegal acts } \\
\text { Deceitfulness, conning } \\
\text { Impulsivity, failure to plan ahead } \\
\text { Lack of remorse }\end{array}$ & $\begin{array}{l}\text { Criminal versatility } \\
\text { Pathological lying, conning } \\
\text { Impulsivity, lack of goals } \\
\text { Lack of remorse or guilt }\end{array}$ \\
\hline $\begin{array}{l}\text { Borderline } \\
\text { personality disorder }\end{array}$ & $\begin{array}{l}\text { Unstable interpersonal relationships } \\
\text { Impulsive sexual behaviour }\end{array}$ & $\begin{array}{l}\text { Many short-term marital relationships } \\
\text { Promiscuous sexual behaviour }\end{array}$ \\
\hline $\begin{array}{l}\text { Histrionic } \\
\text { personality disorder }\end{array}$ & Shallow emotions & Poor behavioural controls \\
\hline $\begin{array}{l}\text { Narcissistic } \\
\text { personality disorder }\end{array}$ & Exploits others for own gain & Shallow affect \\
& Grandiose sense of self-importance & Manipulative \\
\end{tabular}

PCL-R, Psychopathy Checklist - Revised. prisoners (Coid 2009b) in the UK. Psychopathic traits may occur in children, remaining relatively stable throughout adolescence and into adulthood (Frick 2003a; Loney 2007; Lynam 2007). Even early in life, psychopathic traits (named 'callousunemotional' traits when present in children) distinguish these youngsters from other children with conduct disorder with regard to the onset and severity of their antisocial behaviour and the risk of associated harm. Children with both conduct disorder and callous-unemotional traits present with more severe behaviour (Dolan 2004; Frick 2005), have a greater likelihood of their antisocial behaviour persisting into adulthood and manifesting as antisocial personality disorder and psychopathy (Frick 2003b; Lynam 2007), and have a higher risk of future substance use disorders and other adverse outcomes (Lynam 2005).

Studies also suggest that conduct disorder with callous-unemotional traits has a stronger genetic basis than conduct disorder alone (Viding 2005), sharing unique risk factors and a significantly greater heritability rate than noncallous-unemotional groups (Frick 2006). Hence, psychopathy has been viewed as an early-onset developmental disorder, with specific genetic and neurocognitive constraints (Blair 2005). Nevertheless, many authors also emphasise the importance of not applying the term 'psychopath' to children to avoid stigma, and because decisions about the individual case based on the construct are speculative owing to limitations in the evidence base (Johnstone 2007).

\section{Psychopathy and its relation to antisocial personality disorder}

As noted earlier, severe emotional dysfunction (e.g. lack of guilt or victim empathy) is necessary for a diagnosis of psychopathy, but not for antisocial personality disorder. Psychopathy is also distinguished by high levels of both reactive (elicited by frustration) and instrumental (goaldirected) violence (Blair 2001). Further, prevalence rates differ between antisocial personality disorder and psychopathy, suggesting that these diagnoses are not equivalent. In the UK, rates of antisocial personality disorder are estimated at up to $3 \%$ in the general population (Coid 2003) and up to $80 \%$ among prisoners (Hare 2003). This compares with less than $1 \%$ for psychopathy in the general population (Coid 2009a) and just under $8 \%$ among prisoners (Coid 2009b).

Although most adult offenders with psychopathy meet criteria for antisocial personality disorder, only about $30 \%$ of those with antisocial personality disorder have psychopathy (Hart 1997). This 
has led to the view that psychopathy should be regarded as a particularly severe subtype of antisocial personality disorder (Dolan 2007).

\section{Borderline personality disorder}

Borderline personality disorder is characterised by instability in interpersonal relationships, self-image and emotion regulation and marked impulsivity. Individuals with borderline personality disorder are at a greater risk of selfinjurious behaviour and suicide compared with the general population (Oumaya 2008). The incidence of borderline personality disorder in the general population ranges from 0.7 to $2 \%$ (Torgersen 2001; Coid 2003) to over 20\% in psychiatric settings (American Psychiatric Association 2000) and, in contrast to antisocial personality disorder and psychopathy, is diagnosed more frequently in women - although this may reflect bias and not true gender distribution (Chanen 2008). Selfharming behaviour of individuals with borderline personality disorder contrasts with the outwardly directed aggression characteristic of antisocial personality disorder and psychopathy.

\section{Narcissistic personality disorder}

Narcissistic traits include grandiosity, need for admiration and lack of empathy. The estimated rates of narcissistic personality disorder in the general population range from 0.8 to $4 \%$ (Torgersen 2001; Kay 2008), and may decline with increasing age in adulthood (Stinson 2008). Narcissistic personality disorder is commonly comorbid with antisocial personality disorder (e.g. borderline personality disorder and histrionic personality disorder; Stuart 1998). Like borderline personality disorder, it is associated with an elevated risk of suicide (Ronningstam 2008). Neural correlates of narcissistic personality disorder are unknown, although the neural correlates of particular traits (e.g. lack of empathy) are being investigated in relation to psychopathy (see below).

\section{Histrionic personality disorder}

Histrionic traits include excessive emotionality, attention seeking and a seductive demeanour. The general population rate of histrionic personality disorder is around $2 \%$, with no gender difference in prevalence (Grant 2004). Neural correlates of histrionic personality disorder have not been investigated.

\section{Neuroimaging correlates of psychopathy}

A number of neural regions are thought to underlie the core deficits seen in psychopathy, in particular the amygdala and prefrontal cortex.
The functional significance of these and other key regions will be outlined here, followed by a brief overview of relevant neuroimaging findings.

\section{Amygdala \\ Emotional dysfunction}

Research on the neurobiological basis of emotional dysfunction in psychopathy has focused on the amygdala because of its role in emotion processing (particularly of fearful expressions) and emotional learning. For example, patients with amygdala lesions have deficits in the recognition of fearful expressions (Adolphs 1999). Further, in healthy individuals the amygdala is more active during processing of fear and disgust relative to happy and neutral expressions (Costafreda 2008). Also, the amygdala is critically involved in stimulusreinforcer association learning (Rolls 2000), which contributes to moral socialisation - for example, by learning to avoid antisocial behaviour because of its association with emotionally negative outcomes. In particular, the psychologist James Blair hypothesised that in healthy individuals distress cues (such as facial and vocal expressions of fear) function as aversive unconditioned stimuli that elicit empathic responses (feeling the distress of others) (Blair 1995, 2005). In this view, amygdala dysfunction in the 'at risk' child with callous-unemotional traits and in the adult with psychopathy results in insensitivity to distress cues and failure to learn to avoid behaviour that engenders distress in others.

\section{Processing distress cues}

Several lines of evidence now support the view that children with callous-unemotional traits and adults with psychopathy have deficits in processing distress cues, in association with abnormalities of the amygdala. For example, a recent metaanalysis has shown that relative to control groups, antisocial populations show significant deficits in recognising fearful, sad and surprised expressions, with a significantly greater deficit in fear recognition relative to other expressions (Marsh 2008a). Individuals with psychopathy show reduced potentiation of the eye blink startle reflex by visual threat primes (Patrick 1993), which is related to amygdala function. They also show reduced autonomic responsiveness to distress cues (e.g. a crying face), but not threatening or neutral images (Blair 1997). These selective deficits in autonomic responses to facial distress cues are likely to be related to amygdala dysfunction. For example, adolescents with conduct disorder and callous-unemotional traits show reduced amygdala responses to fearful expressions relative 
to controls (Marsh 2008b; Jones 2009). Also, compared with controls, adults with psychopathy show an atypical pattern of greater visual cortical (fusiform gyrus) activity in response to neutral rather than fearful expressions, and also reduced fusiform gyrus activity in response to fearful expressions. This may indicate reduced feedback modulation of fusiform gyrus by the amygdala during fear processing, and contribute to deficits in the recognition of and affective responsiveness to fearful expressions (Deeley 2006).

Reduced amygdala activation was also found in high PCL-R scoring adults during moral decisionmaking tasks (Glenn 2009).

\section{Structure and function of amygdala}

At a structural level, a recent study has shown morphological differences in the amygdala of individuals with psychopathy (Yang 2009). In addition, volumes were correlated negatively with both total and two-factor PCL-R scores, especially Factor 1. In summary, people with psychopathy show evidence of abnormalities of amygdala structure and function that are related both to clinical features and to the underlying information processing deficits - such as impaired emotion recognition, empathy and associative learning which may help explain them.

\section{Emotional processing and learning}

However, it should also be emphasised that in addition to findings of abnormalities in processing distress cues and the structure and function of the amygdala, there is increasing evidence of abnormalities in distributed brain systems involved in emotional processing and learning. For example, significant differences are seen between healthy individuals and those with psychopathy during fear conditioning. In in fear conditioning paradigms, a previously neutral stimulus is paired with an aversive cue (unconditioned stimulus) so that the neutral stimulus alone will become aversive. While acquiring this association, people with psychopathy show significantly less activity of amygdala, orbitofrontal cortex, anterior cingulate cortex and insula than healthy controls, and additionally fail to show conditioned skin conductance response to presentations of the neutral stimulus (Birbaumer 2005).

Another study employing an affective memory task reported reduced affect-related activity in the amygdala/hippocampal formation, parahippocampal gyrus, ventral striatum and in the anterior and posterior cingulate gyri in criminals with psychopathy compared with controls (Kiehl 2001). The criminals also showed evidence of overactivation in bilateral frontotemporal cortices when processing affective stimuli.

Hence, individuals with psychopathy show differences in distributed brain systems involved in emotion processing and memory in two kinds of emotional learning task. Widespread neurobiological differences in responding to and learning about emotive stimuli may contribute to the deficient affective experience and fearlessness. These differences may be in addition to more specific deficits in processing and learning from distress cues that may account for impairments in empathy and the use of instrumental aggression.

\section{Prefrontal cortex}

The importance of the frontal lobes to social behaviour was first recognised in the 19th century following the case of Phineas Gage, in whom frontal lobe damage resulted in profound personality change marked by inappropriate social behaviour (Harlow 1869). A 'frontal lobe' syndrome was subsequently described based on clinical observation of the behaviour of patients with frontal lobe lesions (Lishman 1998). Characteristic features included apathy, emotional lability, lack of social awareness, unconcern for social rules, impulsiveness and frustrative aggression (more commonly known as reactive aggression). This has led to the suggestion that related traits in psychopathy and other personality disorders may also result from frontal lobe abnormalities (Damasio 2000).

Subsequent advances in neuroimaging have allowed the neuropsychological, symptom and trait associations of frontal regions in clinical populations to be defined with increasing precision. Key regions include the prefrontal cortex (frontal regions anterior to motor cortices) and its subdivisions (anterior portions of dorsolateral and medial cortices, and the orbital cortex). The ventromedial prefrontal cortex is an additional term used to refer to the orbitofrontal and/or the ventral portion of the medial wall of the frontal lobe (Stuss 2002). Lesion-deficit studies demonstrate that damage to the ventromedial prefrontal cortex in particular is associated with an increased risk of reactive aggression (Blair 2000). Furthermore, a recent study showed ventromedial prefrontal cortex damage to be associated with deficits in moral judgement. Vignettes detailing failed attempts at harming others were judged as more morally permissible by patients with ventromedial prefrontal cortex lesions compared with controls without such lesions (Young 2010).

Some studies have examined prefrontal or frontal cortex as a whole rather than its subdivisions. For 
example, two studies reported reduced prefrontal (Yang 2005) or frontal (Muller 2008) grey matter volume in adults with psychopathy. Also, higher total as well as subfactor psychopathy scores (arrogant/deceptive, affective and impulsive/ unstable) are associated with low prefrontal grey volume (Yang 2005). Further, cortical blood perfusion measured with single photon emission computed tomography (SPECT) was found to be inversely related to PCL subscores in the frontal and temporal lobes of violent offenders (Factor 1, 'disturbed interpersonal attitudes') (Soderstrom 2002). Hence, there is evidence of reduced prefrontal volume and abnormal frontal and temporal blood flow in individuals with psychopathy relative to controls.

However, other studies have revealed more specific associations between psychopathic traits and subregions of the prefrontal cortex. In particular, the association between ventromedial prefrontal cortex damage and reactive aggression in patients with brain injury is mirrored by impairments of ventromedial prefrontal cortex structure and function in individuals with psychopathy, among other abnormalities. For example, one study revealed reduced grey matter volume in the orbitofrontal cortex, frontopolar cortex and postcentral gyri in adult males with antisocial personality disorder relative to controls, with individuals with psychopathy showing the smallest volumes in these areas (Tiihonen 2008).

A recent study of children with callousunemotional traits and conduct disorder reported increased grey matter concentration in medial orbitofrontal cortex and anterior cingulate cortex (De Brito 2009). Given evidence that callousunemotional traits in childhood may contribute to the development of adult psychopathy (Lynam 2007), these findings may indicate an early developmental origin of prefrontal abnormalities in individuals at risk of adult psychopathy.

\section{Neuropsychological deficits}

These findings raise the question of how abnormalities of prefrontal cortical structure and function contribute to emotional dysfunction and/or antisocial behaviour. Neuropsychological studies attempt to identify impairments in information processing linked to abnormal brain structure and function that contribute to clinical phenotypes. Here, we consider two models of neuropsychological deficits in psychopathy linked to ventromedial prefrontal cortex dysfunction, tested by reversal learning and gambling tasks respectively. In individuals with psychopathy, both tasks may show differences in affective learning associated with ventromedial prefrontal cortex dysfunction that contributes to insensitivity to risk and punishment and recidivism.

\section{Reversal learning}

On tests of reversal learning, individuals are required to alter a dominant rewarded response when task contingency is reversed (a previously rewarded response is now punished). Impaired reversal learning performance by individuals with ventromedial prefrontal cortex damage highlights involvement of this region in this task (Fellows 2003). Individuals with psychopathy show greater response perseveration and during functional magnetic resonance imaging (fMRI) display aberrant activation of ventromedial prefrontal cortex during the reversal phase (Budhani 2007; Finger 2008). Increased ventromedial prefrontal cortex activity to punished error may underpin an inability to respond appropriately to aversive reinforcement in order to regulate behaviour (Rolls 1994).

\section{Gambling tasks}

Ventromedial prefrontal cortex dysfunction in psychopathy is also suggested by response patterns on the Iowa Gambling Task that resemble those of patients with orbitofrontal cortex damage (Bechara 1994; Mitchell 2002; van Honk 2002). This task requires individuals to choose cards from four decks of playing cards in order to receive rewards (financial gain) and avoid punishment (financial loss). The four decks are unequally weighted for losses and gains, with two decks consistently producing both high rewards and high losses and the other two small rewards and small losses. Over time, healthy individuals choose the latter two packs to produce a net gain. By contrast, individuals with ventromedial prefrontal cortex lesions show no bias towards these safer packs, demonstrating this region's importance in this type of decision-making (Bechara 1994). Studies have shown that individuals with subclinical psychopathy (van Honk 2002), children with callous-unemotional traits (Blair 2001) and adults with psychopathy (Mitchell 2002) perform similarly to patients with ventromedial prefrontal cortex lesions on gambling tasks.

\section{Frustration/aggression}

Ventromedial prefrontal cortex dysfunction is also associated with an increased risk of reactive aggression in both individuals with brain injury and individuals with psychopathy (Blair 2000). Possible explanations of this association include increased frustration due to perseveration of 
unsuccessful responses or recurrent social conflict because of a more general inability to suppress impulses and desires (including aggressive impulses when challenged or threatened).

\section{Disconnectivity between prefrontal cortex and limbic regions in psychopathy}

Recent evidence suggests that abnormalities in the structure and function of prefrontal cortex and limbic regions in children with callousunemotional traits and/or individuals with psychopathy should not be viewed in isolation from one another. For example, an fMRI study reported reduced connectivity between the amygdala and prefrontal areas in adolescents with conduct disorder compared with controls, when watching displays of deliberately inflicted pain (Decety 2009).

A study employing diffusion tensor imaging (DTI) found that individuals with psychopathy showed reduced fractional anisotropy - a measure of tract microstructural integrity - of the uncinate fasciculus (Craig 2009). This white matter pathway connects limbic and ventral frontal brain regions. This reduction was inversely correlated with PCL Factor 2 scores (antisocial behaviour). These findings imply that reduced communication between limbic (emotional processing) and frontal (executive) regions may contribute to the behavioural problems seen in populations with antisocial personality disorder.

Individuals with psychopathy show evidence of structural and functional abnormalities of ventromedial prefrontal cortex, amygdala and other components of distributed networks involved in recognising and responding to distress cues, more general emotional processing and learning, behavioural regulation and decision-making.

\section{Neuroimaging correlates of personality disorders}

Few studies of Cluster B personality disorders relate to antisocial and borderline personality disorder. Here these data will be outlined.

\section{Antisocial personality disorder}

Similarly to psychopathy, people with antisocial personality disorder show structural and functional abnormalities of prefrontal cortex. Prefrontal grey matter volume has been found to be reduced in adults (Raine 2000) and children (Huebner 2008) with antisocial personality compared with healthy controls. Medial frontal cortical thinning has been found in antisocial personality disorder (Narayan 2007). Reduced anterior cingulate cortex activation is also seen in children with the disorder while viewing negative affective stimuli (Sterzer 2005; Stadler 2007). Positron emission tomography (PET) studies have reported reduced metabolism in prefrontal areas in violent individuals (Goyer 1994; Volkow 1995).

Reduced volume of temporal regions is also seen in adults (Barkataki 2006) and children (see Sterzer 2009) with antisocial personality disorder, including reduced amygdala volume (Sterzer 2007) and additional hippocampal reduction, with both volumes inversely related to severity of conduct disorder (Huebner 2008). Similarly, reduced amygdala function has been reported in children with conduct disorder to negative emotional visual stimuli (Sterzer 2005), although increased activation was also found (Herpertz 2008).

Similarly, enhanced activation of the amygdala plus striatal and temporal areas were found within a sample of boys with conduct disorder while viewing scenes showing others experiencing pain (Decety 2009). Increased signals in these areas were not shown in the control sample, despite both groups displaying similar activation increases within the pain matrix comprising the anterior insula, medial cingulate cortex, somatosensory cortex and periaqueductal grey. In addition, the authors found reduced functional connectivity between amygdala and prefrontal regions in the conduct disorder group (Decety 2009). However, comparisons of findings across ages should be made with caution.

Existing neuroimaging data indicate that prefrontal and temporal regions show reduced grey matter in antisocial personality disorder, and this may relate to functional deficits additionally seen in these regions. However, studies are not consistent in their methods of allocating or defining clinical groups, making it difficult to draw reliable conclusions from studies of antisocial personality disorder and psychopathy, and when comparing these groups. For example, some studies do not administer the PCL or equivalent measure (e.g. Barkataki 2006) - hence these studies may, in fact, be examining psychopathy and not antisocial personality disorder alone.

\section{Borderline personality disorder}

Neuropsychological assessments of individuals with borderline personality disorder have reported deficits in those tasks reliant on frontal and temporal brain areas (Swirsky-Sacchetti 1993), such as executive function and memory tasks. Emotional processing deficits are also seen in borderline personality disorder, with impaired recognition of emotional faces (Levine 1997) and impairments of emotion recognition when integrating facial 
expressions and prosody (Minzenberg 2006). The increased startle response to aversive stimuli in borderline personality disorder (Hazlett 2007) contrasts with the pattern found in psychopathy (Patrick 1993).

\section{Structural abnormalities}

Structural anomalies found in borderline personality disorder predominantly involve frontal and limbic regions. Significant frontal volume reductions have been found in whole frontal lobe (Lyoo 1998), cingulate cortex (Hazlett 2005) and orbitofrontal cortex (Chanen 2008). Significant reductions in anterior cingulate cortex (Minzenberg 2008) and cingulate gyrus (Soloff 2008) grey matter concentration have also been reported.

A number of MRI studies report structural differences of the amygdala in people with borderline personality disorder compared with healthy controls. However, the direction of these differences varies between studies, with reduced volume (Weniger 2009), increased (Minzenberg 2008) and decreased (Soloff 2008) grey matter concentration, and no volumetric difference (New 2007) being variously reported. Lack of consistency among these findings may arise from methodological differences between studies, including use of mixed- $v$. single-gender cohorts (for discussion of further limitations see Minzenberg 2008).

Structural abnormalities of the hippocampus are also seen in borderline personality disorder, with individuals showing reduced hippocampal volume (Zetzsche 2007; Weniger 2009) and reduced grey matter concentration (Soloff 2008) compared with healthy controls. Additional medial temporal and limbic structural findings include reduced grey matter concentration of parahippocampal gyrus and uncus (Soloff 2008). These findings suggest that common traits of borderline personality disorder and psychopathy (e.g. impulsivity, poor behavioural controls) (Box 1) may be due to similar patterns of frontal and limbic abnormality (Blair 2005).

Differences between activity in frontal and limbic areas

Functional studies also find activity in frontal and limbic areas to differ in borderline personality disorder compared with healthy controls. For example, anterior cingulate cortex hypoactivation is seen during emotional processing (Wingenfeld 2009). Coupled with findings of increased amygdala blood-oxygen level dependency activation during emotional processing (Herpertz 2001; Donegan 2003; Koenigsberg 2009), these results support frontolimbic deficit theories of borderline personality disorder. These propose that amygdala hyperactivation and anterior cingulate cortex hypoactivation to emotional stimuli produce heightened emotional arousal in combination with a reduced ability to inhibit and regulate emotional expression (Wingenfeld 2009). These linked processes could account for the increased intensity of affective experience shown by individuals with borderline personality disorder.

\section{Clinical implications}

From this discussion it can be seen that not only are there common traits between psychopathy and each of the Cluster B personality disorders, but that there is also some overlap in brain anomalies found in the three conditions for which neuroimaging data exist. Shared features of borderline personality disorder and psychopathy may reflect similar cognitive and neural mechanisms. For example, 'emotion' executive dysfunction associated with prefrontal structural and functional abnormalities may contribute to impulsivity, disinhibition, and increased risk of reactive aggression (although other factors may influence whether aggression is directed to self or others). Conversely, the increased affective intensity of borderline personality disorder in contrast to the reduced affective experience of individuals with psychopathy may reflect respective differences in amygdala reactivity. However, it should be noted that clinical features such as 'reactive aggression', 'disinhibition' and 'affective intensity' are not caused by single brain structures acting in isolation. This raises the possibility that the relative contribution of a given structure (e.g. orbitofrontal cortex, amygdala) to a clinical feature (e.g. reactive aggression) may vary depending on the characteristics of other components of relevant brain systems (e.g. anterior cingulate cortex).

\section{Future research}

In general, psychiatric research is increasingly focused on understanding reciprocal influences within and between levels at which people are constituted (e.g. genes, cells, brain systems, social environment), and may ultimately reveal a range of mechanisms by which clinical features such as reactive aggression or impulsivity are produced.

Despite the volume of imaging data related to these conditions, there still remains a great deal to be learnt about the neurobiology of these complex disorders. Identification of neural mechanisms underlying clinical features of psychopathy and other personality disorders may enable improved understanding of diagnosis, aetiology, treatment 
and prognosis. Future research would benefit from the establishment of common technical parameters, study populations and clinical definitions to facilitate comparisons between studies. The distinct, yet overlapping, nature of these diagnoses from a neurobiological as well as a clinical perspective further supports the view that personality disorders may be better classified with dimensional rather than categorical methods.

\section{References}

Adolphs R, Tranel D, Hamann S, et al (1999) Recognition of facial emotion in nine individuals with bilateral amygdala damage. Neuropsychologia 37: 1111-7.

American Psychiatric Association (1980) Diagnostic and Statistical Manual for Mental Disorders (3rd edn) (DSM-III). APA.

American Psychiatric Association (2000) Diagnostic and Statistical Manual for Mental Disorders, Fourth Edition (Text Revision) (DSM-IVTR). APA.

Barkataki I, Kumari V, Das M, et al (2006) Volumetric structural brain abnormalities in men with schizophrenia or antisocial personality disorder. Behavioural Brain Research 169: 239-47.

Bechara A, Damasio AR, Damasio H, et al (1994) Insensitivity to future consequences following damage to human prefrontal cortex. Cognition 50: 7-15.

Birbaumer N, Veit R, Lotze M, et al (2005) Deficient fear conditioning in psychopathy: a functional magnetic resonance imaging study. Archives of General Psychiatry 62: 799-805.

Blackburn R (2005) Psychopathy as a personality construct. In Handbook of Personology and Psychopathology (eds S Strack, T Millon): 271-91. Wiley.

Blair RJ (1995) A cognitive developmental approach to morality: investigating the psychopath. Cognition 57: 1-29.

Blair RJ, Jones L, Clark F, et al (1997) The psychopathic individual: a lack of responsiveness to distress cues? Psychophysiology 34: 192-8.

Blair RJ, Cipolotti L (2000) Impaired social response reversal. A case of 'acquired sociopathy'. Brain 123: 1122-41.

Blair RJ (2001) Neurocognitive models of aggression, the antisocial personality disorders, and psychopathy. Journal of Neurology, Neurosurgery and Psychiatry 71: 727-31

Blair J, Mitchell D, Mitchell DR, et al (2005) The Psychopath: Emotion and the Brain. Blackwell Publishing.

Budhani S, Marsh AA, Pine D, et al (2007) Neural correlates of response reversal: considering acquisition. Neuroimage 34: 1754-65.

Chanen AM, Velakoulis D, Carison K, et al (2008) Orbitofrontal, amygdala and hippocampal volumes in teenagers with first-presentation borderline personality disorder. Psychiatry Research 163: 116-25.

Cleckley HM (1941) The Mask of Sanity. Mosby Medical Library.

Coid J (2003) Epidemiology, public health and the problem of personality disorder. British Journal of Psychiatry 182: s3-10.

Coid J, Yang M, Ullrich S, et al (2009a) Prevalence and correlates of psychopathic traits in the household population of Great Britain. International Journal of Law and Psychiatry 32: 65-73.

Coid J, Yang M, Ullrich S, et al (2009b) Psychopathy among prisoners in England and Wales. International Journal of Law and Psychiatry 32: 134-41.

Costafreda SG, Brammer MJ, David AS, et al (2008) Predictors of amygdala activation during the processing of emotional stimuli: a metaanalysis of 385 PET and fMRI studies. Brain Research Reviews 58 : $57-70$

Craig MC, Catani M, Deeley 0, et al (2009) Altered connections on the road to psychopathy. Molecular Psychiatry 14: 946-53.
Damasio AR (2000) A neural basis for sociopathy. Archives of General Psychiatry 57: 128-9.

De Brito SA, Mechelli A, Wilke M, et al (2009) Size matters: increased grey matter in boys with conduct problems and callous-unemotional traits. Brain 132: 843-52.

Decety J, Michalska KJ, Akitsuki Y, et al (2009) Atypical empathic responses in adolescents with aggressive conduct disorder: a functional MRI investigation. Biological Psychology 80: 203-11.

Deeley Q, Daly E, Surguladze S, et al (2006) Facial emotion processing in criminal psychopathy: preliminary functional magnetic resonance imaging study. British Journal of Psychiatry 189: 533-9.

Dolan M (2004) Psychopathic personality in young people. Advances in Psychiatric Treatment 10: 466-73.

Dolan M, Doyle M (2007) Psychopathy: diagnosis and implications for treatment. Psychiatry 6: 404-8.

Donegan NH, Sanislow CA, Blumberg HP, et al (2003) Amygdala hyperreactivity in borderline personality disorder: implications for emotional dysregulation. Biological Psychiatry 54: 1284-93.

Fellows LK, Farah MJ (2003) Ventromedial frontal cortex mediates affective shifting in humans: evidence from a reversal learning paradigm. Brain 126: 1830-7.

Finger EC, Marsh AA, Mitchell DG, et al (2008) Abnormal ventromedial prefrontal cortex function in children with psychopathic traits during reversal learning. Archives of General Psychiatry 65: 586-94.

Frick PJ, Cornell AH, Barry CT, et al (2003a) Callous-unemotional traits and conduct problems in the prediction of conduct problem severity, aggression, and self-report of delinquency. Journal of Abnormal Child Psychology 31: 457-70.

Frick PJ, Kimonis ER, Dandreaux DM, et al (2003b) The 4 year stability of psychopathic traits in non-referred youth. Behavioral Sciences and the Law 21: 713-36.

Frick PJ, Stickle TR, Dandreaux DM, et al (2005) Callous-unemotional traits in predicting the severity and stability of conduct problems and delinquency. Journal of Abnormal Child Psychology 33: 471-87.

Frick PJ, Dickens C (2006) Current perspectives on conduct disorder. Current Psychiatric Reports 8: 59-72.

Glenn AL, Raine A, Schug RA (2009) The neural correlates of moral decision-making in psychopathy. Molecular Psychiatry 14: 5-6.

Goyer PF, Andreason PJ, Semple WE, et al (1994) Positron-emission tomography and personality disorders. Neuropsychopharmacology 10 : 21-8

Grant BF, Hasin DS, Stinson FS, et al (2004) Prevalence, correlates, and disability of personality disorders in the United States: results from the National Epidemiologic Survey on alcohol and related conditions. Journal of Clinical Psychiatry 65: 948-58.

Hare RD (1980) A research scale for the assessment of psychopathy in criminal populations. Personality and Individual Differences 1: 111-9.

Hare RD (1991) The Hare Psychopathy Checklist - Revised. Multi-Health Systems.

Hare RD (2003) Manual for the Revised Psychopathy Checklist (2nd edn). Multi-Health Systems.

Harlow JM (1869) Recovery from the passage of an iron bar through the head. Reprint: Harlow JM, Miller E (1993) History of Psychiatry 4: 274-81.

Hart SD, Hare RD (1997) Psychopathy: Assessment and Association with Criminal Conduct. Wiley.

Hazlett EA, New AS, Newmark R, et al (2005) Reduced anterior and posterior cingulate gray matter in borderline personality disorder. Biological Psychiatry 58: 614-23.

Hazlett EA, Speiser LJ, Goodman M, et al (2007) Exaggerated affectmodulated startle during unpleasant stimuli in borderline personality disorder. Biological Psychiatry 62: 250-5.

Herpertz SC, Dietrich TM, Wenning B, et al (2001) Evidence of abnormal amygdala functioning in borderline personality disorder: a functional MRI study. Biological Psychiatry 50: 292-8. 
Herpertz SC, Huebner T, Marx I, et al (2008) Emotional processing in male adolescents with childhood-onset conduct disorder. Journal of Child Psychology and Psychiatry and Allied Disciplines 49: 781-91.

Huebner T, Vloet TD, Marx I, et al (2008) Morphometric brain abnormalities in boys with conduct disorder. Journal of the American Academy of Child and Adolescent Psychiatry 47: 540-7.

Johnstone L, Cooke DJ (2007) Psychopathy and young offenders. Psychiatry 6: 429-32.

Jones AP, Laurens KR, Herba CM, et al (2009) Amygdala hypoactivity to fearful faces in boys with conduct problems and callous-unemotional traits. American Journal of Psychiatry 166: 95-102.

Kay J (2008) Toward a clinically more useful model for diagnosing Narcissistic Personality Disorder. American Journal of Psychiatry 168 : 1379-82.

Kiehl KA, Smith AM, Hare RD, et al (2001) Limbic abnormalities in affective processing by criminal psychopaths as revealed by functional magnetic resonance imaging. Biological Psychiatry 50: 677-84.

Kiehl KA (2006) A cognitive neuroscience perspective on psychopathy: evidence for paralimbic system dysfunction. Psychiatry Research 142: $107-28$.

Koenigsberg HW, Siever LJ, Lee H, et al (2009) Neural correlates of emotion processing in borderline personality disorder. Psychiatry Research 172: 192-9.

Levine D, Marziali E, Hood J (1997) Emotion processing in borderline personality disorders. Journal of Nervous and Mental Disease 185: 240-6.

Lishman WA (1998) Organic Psychiatry: The Psychological Consequences of Cerebral Disorder, Third Edition. Blackwell Science.

Loney BR, Taylor J, Butler MA, et al (2007) Adolescent psychopathy features: 6-year temporal stability and the prediction of externalizing symptoms during the transition to adulthood. Aggressive Behavior 33: 242-52.

Lynam DR, Gudonis L (2005) The development of psychopathy. Annual Review of Clinical Psychology 1: 381-407.

Lynam DR, Caspi A, Moffitt TE, et al (2007) Longitudinal evidence that psychopathy scores in early adolescence predict adult psychopathy. Journal of Abnormal Psychology 116: 155-65.

Lyoo IK, Han MH, Cho DY (1998) A brain MRI study in subjects with borderline personality disorder. Journal of Affective Disorders 50 : 235-43.

Marsh AA, Blair RJR (2008a) Deficits in facial affect recognition among antisocial populations: a meta-analysis. Neuroscience and Biobehavioral Reviews 32: 454-65.

Marsh AA, Finger EC, Mitchell DG, et al (2008b) Reduced amygdala response to fearful expressions in children and adolescents with callousunemotional traits and disruptive behavior disorders. American Journal of Psychiatry 165: 712-20.

Minzenberg MJ, Poole JH, Vinogradov S (2006) Social-emotion recognition in borderline personality disorder. Comprehensive Psychiatry 47: 468-74.

Minzenberg MJ, Fan J, New AS, et al (2008) Frontolimbic structural changes in borderline personality disorder. Journal of Psychiatric Research 42: 727-33.

Mitchell DG, Colledge E, Leonard A, et al (2002) Risky decisions and response reversal: is there evidence of orbitofrontal cortex dysfunction in psychopathic individuals? Neuropsychologia 40: 2013-22.

Morana HC, Arboleda-Florez J, Camara FP (2005) Identifying the cutoff score for the PCL-R scale (psychopathy checklist-revised) in a Brazilian forensic population. Forensic Science International 147: 1-8.

Muller JL, Ganssbauer S, Sommer M, et al (2008) Gray matter changes in right superior temporal gyrus in criminal psychopaths. Evidence from voxel-based morphometry. Psychiatry Research 163: 213-22.

Narayan VM, Narr KL, Kumari V, et al (2007) Regional cortical thinning in subjects with violent antisocial personality disorder or schizophrenia. American Journal of Psychiatry 164: 1418-27.
New AS, Hazlett EA, Buchsbaum MS, et al (2007) Amygdala-prefrontal disconnection in borderline personality disorder. Neuropsychopharmacology 32: 1629-40.

Oumaya M, Friedman S, Pham A, et al (2008) Borderline personality disorder, self-mutilation and suicide: literature review. Encephale 34: 452-8.

Patrick CJ, Bradley MM, Lang PJ (1993) Emotion in the criminal psychopath: startle reflex modulation. Journal of Abnormal Psychology 102: 82-92.

Raine A, Lencz T, Bihrle S, et al (2000) Reduced prefrontal gray matter volume and reduced autonomic activity in antisocial personality disorder. Archives of General Psychiatry 57: 119-27.

Reid WH, Gacono C (2000) Treatment of antisocial personality, psychopathy, and other characterologic antisocial syndromes. Behavioral Sciences and the Law 18: 647-62.

Rolls ET, Hornak J, Wade D, et al (1994) Emotion-related learning in patients with social and emotional changes associated with frontal lobe damage. Journal of Neurology, Neurosurgery and Psychiatry 57: 1518-24.

Rolls ET (2000) Precis of the brain and emotion. Behavioral and Brain Sciences 23: 177-91.

Ronningstam E, Weinberger I, Maltsberger JT (2008) Eleven deaths of Mr. K.: contributing factors to suicide in narcissistic personalities. Psychiatry 71: 169-82.

Soderstrom H, Hultin L, Tullberg M, et al (2002) Reduced frontotemporal perfusion in psychopathic personality. Psychiatry Research 114: 81-94.

Soloff P. Nutche J. Goradia D, et al (2008) Structural brain abnormalities in borderline personality disorder: a voxel-based morphometry study. Psychiatry Research 164: 223-36.

Stadler C, Sterzer P, Schmeck K, et al (2007) Reduced anterior cingulate activation in aggressive children and adolescents during affective stimulation: association with temperament traits. Journal of Psychiatric Research 41: 410-7.

Sterzer P, Stadler C, Krebs A, et al (2005) Abnormal neural responses to emotional visual stimuli in adolescents with conduct disorder. Biological Psychiatry 57: 7-15

Sterzer P, Stadler C, Poustka F, et al (2007) A structural neural deficit in adolescents with conduct disorder and its association with lack of empathy. Neuroimage 37: 335-42.

Sterzer P, Stadler C (2009) Neuroimaging of aggressive and violent behaviour in children and adolescents. Frontiers in Behavioural Neuroscience 3: 35

Stinson FS, Dawson DA, Goldstein RB, et al (2008) Prevalence, correlates, disability, and comorbidity of DSM-IV Narcissistic Personality Disorder: results from the Wave 2 National Epidemiologic Survey on alcohol and related conditions. Journal of Clinical Psychiatry 69: 1033-45.

Stuart S, Pfohl B, Battaglia M, et al (1998) The cooccurrence of DSM-III-R personality disorders. Journal of Personality Disorder 12: 302-15.

Stuss DT, Levine B (2002) Adult clinical neuropsychology: lessons from studies of the frontal lobes. Annual Review of Psychology 53: 401-33.

Swirsky-Sacchetti T, Gorton G, Samuel S, et al (1993) Neuropsychological function in borderline personality disorder. Journal of Clinical Psychology 49: 385-96.

Tiihonen J, Rossi R, Laakso MP, et al (2008) Brain anatomy of persistent violent offenders: more rather than less. Psychiatry Research 163: 201-12.

Torgersen S, Kringlen E, Cramer V (2001) The prevalence of personality disorder in a community sample. Archives of General Psychiatry 58 : 590-6.

van Honk J, Hermans EJ, Putman P, et al (2002) Defective somatic markers in sub-clinical psychopathy. Neuroreport 13: 1025-7.

Viding E, Blair RJ, Moffitt TE, et al (2005) Evidence for substantial genetic risk for psychopathy in 7-year-olds. Journal of Child Psychology and Psychiatry and Allied Disciplines 46: 592-7.

Volkow ND, Tancredi LR, Grant C, et al (1995) Brain glucose metabolism in violent psychiatric patients: a preliminary study. Psychiatry Research: Neuroimaging 61: 243-53.
MCO answers

$1 \mathrm{~d} \quad 2$ e 3 a 4 a 5 e 
Weniger G, Lange C, Sachsse U, et al (2009) Reduced amygdala and hippocampus size in trauma-exposed women with borderline personality disorder and without posttraumatic stress disorder. Journal of Psychiatry and Neuroscience 34: 383-8.

Wingenfeld K, Rullkoetter N, Mensebach C, et al (2009) Neural correlates of the individual emotional Stroop in borderline personality disorder. Psychoneuroendocrinology 34: 571-86.

World Health Organization (2004) International Statistical Classification of Diseases and Related Health Problems, Tenth Revision (ICD-10). WHO.
Yang Y, Raine A, Lencz T, et al (2005) Volume reduction in prefrontal gray matter in unsuccessful criminal psychopaths. Biological Psychiatry 57: 1103-8.

Yang Y, Raine A, Narr KL, et al (2009) Localization of deformations within the amygdala in individuals with psychopathy. Archives of General Psychiatry 66: 986-94.

Young L, Bechara A, Tranel D, et al (2010) Damage to ventromedial prefrontal cortex impairs judgment of harmful intent. Neuron 65: 845-51.

Zetzsche T, Preuss UW, Frodl T, et al (2007) Hippocampal volume reduction and history of aggressive behaviour in patients with borderline personality disorder. Psychiatry Research 154: 157-70.

\section{MCOs}

Select the single best option for each question stem

1 According to DSM-IV-TR, psychopathy is:

a an associated feature of antisocial personality disorder

b a distinct personality disorder

c a subcategory of borderline personality disorder

d the same as antisocial personality disorder

e a and $c$.

\section{Borderline personality disorder is} associated with:

a greater male to female incidence

b high risk of self-harm and suicide

c amygdala dysfunction

d emotional processing deficits

e b-d.
3 Neuroimaging research findings can:

a measure differences in brain function between groups

b be compared directly with all other neuroimaging studies

c clearly distinguish psychopathy from antisocial personality disorder

$\mathrm{d}$ be used to diagnose borderline personality disorder

e $b$ and $c$.

4 Antisocial personality disorder:

a is more prevalent than psychopathy

$\mathrm{b}$ is associated with greater and more severe criminality than psychopathy

c can be diagnosed in children

$\mathrm{d}$ can be diagnosed using the PCL-R

e cannot co-occur with psychopathy.

\section{Adult psychopathy is associated with:}

a reduced prefrontal grey matter

b altered visual cortical responses to fearful expressions

c reduced amygdala volume

$\mathrm{d}$ reduced prefrontal grey matter and amygdala volume

e b-d. 